Reviews

\title{
Towards Sustainable Communities: Transition and Transformations in Environmental Policy. Edited by Daniel A. Mazmanian and Michael E. Kraft (1999). Cambridge, MA: The MIT Press, 323 pp.
}

\author{
Reviewed by John Schelhas, Southern Research Station, USDA Forest Service, Tuskegee \\ University, Tuskegee, AL.
}

The focus of this book is on practical efforts to work towards sustainable communities, with "communities" broadly defined to range from urban areas such as Los Angeles to the Great Lakes basin. The book analyzes six case studies using a framework that divides modern environmental policy into three epochs. Epoch 1, in the 1960s and 1970s, was characterized by command and control government regulation of single-issue environmental problems (e.g., air or water pollution). Epoch 2, in the 1980s, was characterized by the balancing of environmental and social economic priorities through market-based and collaborative approaches. Epoch 3, which began in the 1990s, marks the transition to sustainable community approaches that take a comprehensive, multi-resource approach to environmental problems and involve collaboration between different actors and sectors. The book is organized around these three epochs, with three case studies focusing on transitions from Epoch 1 to Epoch 2 [clean air in Los Angeles (Daniel Mazmanian); clean water in the Fox-Wolf watershed, Wisconsin (Michael Kraft and Bruce Johnson); and open-space in California (Daniel Press)]. Three other case studies focus on transitions from Epoch 2 to Epoch 3 [Pittsburgh as an "environmental city" (Franklin Tugwell, Andrew McElwaine, and Michele Fetting); federal transportation policy (Thomas Horan, Hank Dittmar, and Daniel Jordan); and watershed management in the Great Lakes basin (Barry Rabe)].

The book begins with two introductory chapters that provide a clear analytical framework maintained throughout the book. In the first chapter, Daniel Mazmanian and Michael Kraft discuss the three epochs of the modern environmental movement described above. In doing this, they draw primarily on the environmental issues addressed by, and the experiences of, the U.S. Environmental Protection Agency (EPA) - clean air, clean water, and the urban environment. In spite of this emphasis, they cast their arguments broadly enough to touch on issues of land preservation and ecosystem management.

The second chapter, by Lamont Hempel, lays out the book's conceptual perspective on sustainability. The approach is one of analyzing the broad social movement that has coalesced around the sustainability term, rather than defining sustainability. "Sustainability" is seen as ambiguous enough to be embraced by diverse interests, while coherent enough to inspire movement in a particular direction. The sustainability movement is defined as one that: (1) seeks to build "communities in which environmental quality, social justice, and economic vitality cohere in some sustained fashion," (2) within a geographically defined area, (3) by an at least partially coordinated set of interest groups from the public, business, and non-profit sectors. Hempel, noting that most discussion of sustainability is at the "high concept level," rather than the "practical problem-solving level," seeks to lay out some guidelines for the difficult task of operationalizing sustainability. His approach, which he takes the time to critique in terms of real world practicality, is one of constructing reliable sustainability indicators that can be fit to diverse communities and then monitored for changes in direction or intensity. The remainder of the book makes clear that this process is not carried out by an individual governing agency, but rather is the sum of processes of collaboration and competition among a diverse set of interest groups and actors over time.

The six case studies provide the real-world grounding for the book, and serve to illustrate the trends in environmental policy across the three epochs. To their credit, the authors consistently avoid the tendency, common in disciplinary discussions of environmental policy, to compare actual historical policy experiences (e.g., government regulation) to theoretical or idealistic accounts of alternative policies (e.g., market-based incentives or community-based approaches). Instead, each case provides a thorough critique of the pros and cons of different approaches, along with discussions about how these different approaches have worked in concert. For example, the success of top-down, coercive government laws and regulation in cleaning up air and water in the 1960s and 1970s is fully acknowledged. But the authors go on to show how the real limits of these approaches lay the groundwork for the market-based and collaborative approaches of Epoch 2. Rather than full embracing new approaches, however, the authors show the continuing role of laws and regulations in bringing stakeholders into collaborative processes and addressing the deficiencies of market-based mechanisms.

It is notable that the authors - perhaps because of their urban and regional planning backgrounds - easily 
Reviews

come to terms with the productive and economic side of human communities. This is in stark contrast to the literature on biodiversity and sustainability, which has produced a great deal of acrimonious debate between biodiversity conservation and sustainable development interests rather than acknowledging that both are important and moving on to seek practical ways advance both concerns. Using the real world cases that it presents, the book highlights how efforts to address environmental and social issues comprehensively have arisen out of the limitations of prior efforts to address these issues in isolation. The book is firmly grounded in the inclusive beliefs that: (1) we can simultaneously work toward the goals of environmental quality, social justice, and economic vitality; (2) each of the different sectors - public, private, and non-profit - has a contribution to make; and (3) real progress is made when these players are able to find areas of common concern and develop corresponding actions.

None of the authors find unqualified successes in the cases that they discuss, and they pragmatically note failures and successes, as well as hopeful and discouraging signs for the future. The perspective that emerges is that the quest for sustainable communities is a turbulent process of interacting interest groups, fragile progress mixed with setbacks, solving of old problems and discovery of new ones. This process is messy, but produces concrete improvements in many environmental and social indicators over time. Yet problems are rarely fully solved, and new problems emerge, making sustainability always a work-in-progress. By fully embracing the complexity and uncertainty found in the cases, the authors position themselves to lay out a strong agenda for future research and practice. (In keeping with the inclusive nature of the book, the authors are able to discuss both implementation needs and research needs in a synergistic way, rather than seeing one as being more important than the other)

Kraft and Mazmanian effectively sum up the lessons of the book and lay out a future agenda in their concluding chapter. They see environmental policy at the beginning of what could be a profound transformation towards a sustainable communities approach, but with the direction and extent of this transformation depending on how certain key challenges are met. One of these challenges is developing public involvement and governance processes that can address the ever-present conflicts in goals among interest groups and find sufficient consensus that to support concrete initiatives. A second challenge is developing indicators and monitoring methods that can inform policy choices. The third challenge is for researchers to conduct comparative research involving cases with different histories, types and levels of initiatives, and degree of success or failure to produce the empirical knowledge and theories (social, cultural, economic, and political) that can bring about shifts in human behavior and progress towards sustainable communities.

This book makes a significant contribution towards the theory and practice of sustainability by analyzing a series of case studies with the common framework of the three epochs of modern environmental policy. Although the book is clearly much stronger on urban and regional planning issues than natural resource management issues (i.e., issues within the scope of EPA's authority, rather than within the domains of the US Departments of Interior and Agriculture), it successfully lays out a strong framework that can be applied to many aspects of recent and current environmental policy. Its pragmatic focus will provide useful guidance to practitioners who are working in environmental policy and management, while at the same time providing a real-world anchor that can guide academic and applied researchers in their efforts to contribute to environmental policy and management.

\section{Paradise for Sale: A Parable of Nature. By Carl N. McDaniel and John M. Gowdy. Berkeley, Los Angeles and London: University of California Press, 2000, xiv, 225 pp}

\section{Reviewed by David Zurick, Department of Geography, Eastern Kentucky University, Richmond, KY 40475}

The authors selected Nauru, a tiny tropical island in the western Pacific Ocean, as metaphor of their grim environmental trajectory of the world. It was not a bad choice. The lunar landscape of Nauru counters most intuition about Polynesia as paradise. In place of coconut palms and lush gardens, one finds on Nauru that much of nature has been eliminated and eighty percent of the land rendered useless, a wasteland, because of unbridled phosphate mining since 1901. During the past century, the island, which supported human life for 2000 years, has become incapable of self-supporting its inhabitants, even while they became richer in the process. The environmental collapse in Nauru paralleled the emergence of the global economy, noted in the island's history of colonialism, modern-day politics of 